\title{
JUSTIÇA RESTAURATIVA NUMA POLÍTICA HUMANIZADORA E NÃO NECESSARIAMENTE DE PERDÃO: UM OLHAR CRÍTICO E REFLEXIVO NA RESOLUÇÃO 225 DO CNJ/2016
}

\author{
RESTORING JUSTICE AN HUMANIZING POLICY AND \\ NOT NECESSARILY OF FORGIVENESS: A CRITICAL AND \\ REFLECTIVE LOOK AT RESOLUTION 225 OF THE CNJ / 2016
}

Marli Marlene Moraes da Costa ${ }^{1}$

Rosane Teresinha Carvalho Porto ${ }^{2}$

Recebido em: 30/05/2017

Aprovado em: 18/08/2017

\section{RESUMO}

No atual cenário brasileiro, onde as instituições estão fragilizadas e o cidadão corrompido, é preciso reinventar a justiça com práticas inovadoras como

\footnotetext{
${ }^{1}$ Doutora em Direito pela Universidade Federal de Santa Catarina - UFSC, com pós-doutorado em Direito pela Universidad de Burgos - Espanha, com bolsa CAPES. Professora da Graduação e Coordenadora do Programa de Pós-Graduação em Direito - Mestrado e Doutorado da Universidade de Santa Cruz do Sul UNISC. Coordenadora do Grupo de Estudos Direito, Cidadania \& Políticas Públicas na mesma Universidade. Especialista em Direito Privado. Professora do Curso de Direito da Fundação Educacional Machado de Assis - FEMA. Psicóloga com Especialização em Terapia Familiar. Autora de livros e artigos em revistas especializadas. E-mail: marlim@unisc.br

2 Doutora em Direito pela UNISC. Mestre em Direito na área de concentração: Políticas Públicas de Inclusão Social com bolsa da Coordenação de Aperfeiçoamento de Pessoal de Nível Superior - CAPES. Policial Militar. Professora de Direito da Infância e da Juventude, na UNISC, Subcoordenadora do Curso de Direito UNISC/ Sobradinho. Editora Adjunta da Revista do Direito da UNISC. Estuda temáticas voltadas a criança e adolescente, violência, criminologia, gênero e Justiça Restaurativa. Integrante do Grupo Direito, Cidadania e Políticas Públicas coordenado pela Professora Pós-Doutora Marli Marlene Moraes da Costa. Email: rosaneporto@unisc.br
} 
as da Justiça Restaurativa. A sua multidimensionalidade pode aproximar a comunidade do Judiciário, e com efeito contribuir para o acesso à justiça das pessoas. Entretanto, com a implementação da Justiça Restaurativa no Brasil, existem alguns desafios como o da cultura jurídica a ser superado para a sua efetividade dentro da comunidade. Além disso, mister repensar na sua metodologia, nas suas finalidades e no papel do facilitador em meio a tudo isso. $\mathrm{O}$ presente estudo procura estudar a Justiça Restaurativa, acreditando ser uma política humanizadora, enquanto proposta de diálogo e alteridade, com base em um olhar crítico e reflexivo na Resolução 225 do CNJ /2016. Por conta disso, se questiona: A Justiça Restaurativa é a busca pelo perdão do outro? Com isso seria um exercício a alteridade? $\mathrm{O}$ artigo foi pensado em três partes, sendo a primeira responsável por realizar a contextualização teórico e prático da Justiça Restaurativa, sendo o círculo de construção de paz uma de suas principais metodologias; a segunda em abordar o papel do facilitador restaurativo. E por fim, o sentido do perdão dentro dessas práticas. Os resultados obtidos demonstraram que ainda, a sua implementação é incipiente, existindo algumas resistências, por conta da cultura jurídica dominante e da política de controle social. Para tanto, utilizou-se o método de abordagem dedutivo, adotando o procedimento histórico-crítico e o monográfico, e como técnica de pesquisa bibliográfica e documental.

\title{
PALAVRAS-CHAVE
}

Diálogo; Cultura jurídica; Justiça restaurativa; Perdão.

\begin{abstract}
In the current Brazilian scenario, where institutions are fragile and the citizen corrupted, it is necessary to reinvent justice with innovative practices such as Restorative Justice. Its multidimensionality can bring the community closer to the Judiciary, and in effect contribute to people's access to justice. However, with the implementation of Restorative Justice in Brazil, there are some challenges such as the legal culture to be overcome for its effectiveness within the community. In addition, it is necessary to rethink its methodology, its aims and the role of the facilitator in the midst of all this. The present study seeks to study Restorative Justice, believing it to be a humanizing policy, as a proposal for dialogue and otherness, based on a critical and reflexive look in Resolution
\end{abstract}


225 of the CNJ / 2016. Because of this, the question is: Is restorative justice the search for forgiveness of the other? With this would be an exercise otherness? The article was thought in three parts, being the first one responsible for realizing the theoretical and practical contextualization of Restorative Justice, being the circle of peace building one of its main methodologies; The second to address the role of the restorative facilitator. And finally, the sense of forgiveness within these practices. The results showed that, still, its implementation is incipient, and there is some resistance, due to the dominant legal culture and the social control policy. For that, the method of deductive approach was used, adopting the historical-critical and the monographic procedure, and as bibliographical and documentary research technique.

\section{KEYWORDS}

Dialogue; Forgiveness; Juridical culture; Restorative justic. 


\section{Introdução}

O presente artigo procura estudar a Justiça Restaurativa, acreditando ser uma política humanizadora, enquanto proposta de diálogo e alteridade, com base em um olhar crítico e reflexivo na Resolução 225 do CNJ/2016. Por conta disso, se questiona: A Justiça Restaurativa é a busca pelo perdão do outro? Com isso seria um exercício a alteridade? O artigo foi pensado em três partes, sendo a primeira responsável por realizar a contextualização teórico e prático da Justiça Restaurativa, sendo o círculo de construção de paz uma de suas principais metodologias; a segunda em abordar o papel do facilitador restaurativo. E por fim, o sentido do perdão dentro dessas práticas. Os resultados obtidos demonstraram que ainda, a sua implementação é incipiente,

Muitos são os conflitos entre as pessoas que demandam de um outro olhar reflexivo e humanizado. Por vezes, elas recorrem ao Poder Judiciário para ter a garantia do acesso à justiça, bem como a solução para a dor, a indiferença e a injustiça sofrida, em virtude da incompreensão e a outra natureza do conflito como mecanismo transformador e propulsor, necessário ao crescimento do ser humano enquanto pessoa. Nessa dimensão surgem as políticas alternativas de tratamento de conflitos, tais como: a mediação, a conciliação, e a que mais no momento interessa trabalhar: a Justiça Restaurativa.

É importante destacar o fato da Justiça Restaurativa ser multidimensional, ou seja, é um processo comunitário que envolve três concepções, quais sejam: o encontro, a reparação e a transformação das pessoas.

Então, pelo fato de as comunidades serem distintas uma das outras, é necessário que a Justiça Restaurativa esteja sempre se adaptando, a fim de fortalecer as relações entre os indivíduos e a comunidade, contribuindo para que também os próprios cidadãos assumam o papel de pacificar seus próprios conflitos, atenuando os índices de violência.

As práticas restaurativas propriamente ditas no Brasil aplicam os círculos de construção da paz e priorizam a harmonia e o (r)estabelecimento do diálogo entre os cidadãos. A partir disso, busca-se romper com os paradoxos punitivos e retributivos que voltam-se para o autor do fato delituoso, objetivando uma escuta atenta para a vítima.

A Justiça Restaurativa compensa os danos gerados por meio de compromissos futuros que promovam a restauração dos vínculos sociais mais harmô- 
nicos. Além disso, busca promover sentimentos e relacionamentos positivos, não se delimitando a redução da criminalidade, mas ir além, ou seja, em promover a regeneração dos vínculos rompidos e fragilizados.

O que diferencia a Justiça Restaurativa, então, de uma maneira geral da mediação e da conciliação está na sua forma de encarar e agir fundamentadas em valores e princípios como o respeito, a honestidade, a humildade, a responsabilidade, a esperança, o empoderamento, a interconexão, a autonomia, a participação, e a busca de sentido e de pertencimento na responsabilização pelos danos causados.

Baseia-se numa ética de inclusão e de responsabilidade social, promovendo o conceito de responsabilidade ativa. Assim, assume-se como verdadeira a premissa de que o impacto de cada atendimento guiado pelos valores como o agradecimento, a compaixação, a solidariedade não se restringe apenas ao ofensor e a vítma do dano ocasionado pelo crime, mas alcança seu entorno familiar e comunitário.

Por fim, ressalta-se que, muito embora ser a Justiça Restaurativa um movimento ainda novo e emergente, existe um crescente consenso internacional em relação a seus princípios, inclusive documentos da ONU (Organização Nacional das Nações Unidas) e da União Européia, que validam e recomendam as práticas restaurativas para todos os países.

\section{Entre e sente-se: Bem-vindo a Justiça Restaurativa!}

A Justiça Restaurativa é um convite ao encontro e ao direito a palavra, o que não necessariamente implicaria na busca pelo perdão. Os primeiros trabalhos com este tema, se deu na segunda metade da década de 1970, em decorrência de uma insatisfação acentuada com o sistema de justiça criminal tradicional, apresentado desde um panorama obscuro e ineficiente que justificaria a adoção de um outro modelo de administração de conflitos, sendo no caso o das práticas restaurativas (ACHUTI, 2014).

A insatisfação cada vez mais veemente com o sistema de justiça criminal e tradicional, o Brasil aderiu a Justiça Restaurativa enquanto outra abordagem complementar de pacificação social de conflitos, a partir principalmente da Resolução 2002/12 sobre "Princípios básicos a aplicação do programa de Justiça Restaurativa em Mediação Penal", aprovada em abril de 2002 pelo ECOSOC. 
Esta resolução carece ainda de força vinculante por seu caráter programático, mas interessa porque proclama a utilidade de programas de justiça reparadora em todas as fases do processo da justiça criminal, e insta os Estados-membros a introduzi-los, comprometendo as autoridades policiais, judiciais e comunitárias na nova cultura restaurativa.

A Resolução que se refere explicitamente à "mediação", à "conciliação" e a "conversas e reuniões para decidir condenações" com uma terminologia inequivocamente anglo-americana, encarrega-se mais em definir o "processo reparador", do que do próprio conceito de "justiça reparadora", e proclama que este modelo de justiça "promove a harmonia social mediante a recuperação das vítimas, dos delinquentes e das comunidades". É imperioso mencionar que tal recomendação não tem clareza ou objetividade conceitual, preceituando a seara procedimental, o que ainda hoje repercute nas práticas difundidas extrajudicialmente e judicialmente.

O termo "Justiça Restaurativa", até onde se tem conhecimento, foi utilizado pela primeira vez enquanto "Justiça Reparadora", no contexto da Justiça Criminal por Albert Eglash, ele sugeriu que há três tipos de justiça criminal: “(1) a justiça retributiva, baseada na punição; (2) a justiça distributiva, baseada no tratamento terapêutico de delinquentes; e (3) a justiça restaurativa, baseada na restituição" . (VAN NESS, 2010).

Ambos os modelos de punição e de tratamento, observou ele, focam nas ações dos criminosos, negam a participação da vítima no processo de justiça, e requerem a participação meramente passiva do criminoso. A Justiça Restaurativa, por outro lado, foca nos efeitos nocivos das ações dos criminosos e envolve ativamente vítimas e agressores no processo de reparação e reabilitação (VAN NESS, 2010).

Na esteira Santana aduz que a Justiça restaurativa é "una Justicia más humana, dialogada, participativa, cuyo principal propósito es restaurar la paz, reparar el daño, prevenir la reconciliación, la mediación, la restitución y la compensación entre la víctima, el autor del hecho delictivo y la comunidade" (SANTANA, 2007).

Por outro lado, Zehr descreve a Justiça restaurativa da seguinte forma:

ela tem foco nos danos e consequentes necessidades (da vítima, mas também da comunidade e do ofensor); trata das obrigações resultantes desses danos (obrigações do ofensor mas também da comunidade e da sociedade). Utiliza processos inclusivos e cooperativos; envolve todos que têm interesse na situação (vítimas, ofensores, a comunidade, a sociedade) e busca corrigir os males. (ZEHR, 2008) 
O aumento da criminalidade e da violência tem mobilizado a sociedade contemporânea. Isso demanda criatividade, para tanto é preciso avançar para um sistema multiportas que ofereça respostas diferentes e mais adequadas a essas chagas sociais e patológicas. Nisso, se pode afirmar que a Justiça Restaurativa seria uma dessas portas, com abertura para uma resposta adequada a um considerável número de delitos.

Nesse texto ainda é importante abordar a diferença e a singularidade dos institutos da mediação, conciliação e Justiça Restaurativa, sendo passíveis de confusão em um conhecimento preliminar, pois há uma linha tênue entre estes, uma vez que apresentam uma proposta e objetivos similares.

\subsection{A busca pela pacificação social e a resolução eficaz de conflitos}

Lamentalvemente o Judiciário não administrar satisfatoriamente os conflitos, necessitando cada vez mais da interdisciplinariedade para proporcionar espaços criativos e de diálogo a comunidade. Em outras palavras, potencializar os métodos extrajudiciais.

É neste interím que se verifica a importância de compreender as diferenças e singularidades da mediação, conciliação e Justiça Restaurativa. Com isso conota-se que:

“a diferença fundamental entre a mediação e a conciliação reside no conteúdo de cada instituto. Na conciliação, o objetivo é o acordo, ou seja, as partes, mesmo adversárias, devem chegar a um acordo para evitar um processo judicial. Na mediação as parte não devem ser entendidas como adversárias e o acordo é conseqüência da real comunicação entre as partes. Na conciliação, o mediador [conciliador] sugere, interfere, aconselha. Na medição, o mediador facilita a comunicação, sem induzir as partes ao acordo". (SALES, 2004, p.38. Apud, MORAES, 2012).

Assim a partir da análise da Resolução . $^{\circ} 125$ do CNJ é possível compreender a proposta da medicação e da conciliação. A primeira se baseia na construção da solução do problema pelas partes envolvidas, tendo como apoio a presença de um profissional treinado chamado de mediador, que não intervém diretamente no processo, mas através de técnicas estudadas incita às partes a compreender, a reparar e a solucionar o conflito existente. Já o segundo instituto, o da conciliação, tem a presença do conciliador que escuta as partes e 
propõe de forma direta a estas vantagens e desvantagens, até se chegar a um acordo entre ambos, antes de se judicializar qualquer questão.

Quando se fala em Justiça Restaurativa em conformidade com aa Resolução n. ${ }^{\circ} 225$ do $\mathrm{CNJ}$ é possível ver o apoio normativo à sua difusão aqui no Brasil. Sendo assim, como já visto, as Práticas Restaurativas tem como base o resgate das relações humanas corrompidas após o surgimento de um conflito. Esse resgate das relações é proposto por meio de uma análise profunda das emoções dos envolvidos, da sensibilização entre estes, da reparação do dano causado e da busca pelo perdão, não necessariamente entre os envolvidos.

A Justiça Restaurativa é uma política pública judiciária que visa também a prevenção do surgimento do conflito e do dano, desta forma, nada mais visionário que instituí-la em outros setores, fora o Judiciário, tais como: Centros de integração de ensino especial, escolas e universidades, por exemplo.

\section{Noções fundamentais sobre a Justiça restaurativa e o papel do facilitador}

Em meio a tantas adversidades na sociedade brasileira, dado os períodos oscilantes e incertos sobre o sistema de justiça, que uma outra proposta de justiça enquanto valor de vida e social surge, como uma certa espécie de esperança e utopia social. Está-se tratando da Justiça Restaurativa, que em sentido amplo é o encontro dialógico entre a vítima, o ofensor e os familiares de ambos enquanto representantes da comunidade.

A Justiça Restaurativa não é uma espécie de perdão e de impunidade, vai além dessa construção imaginária das pessoas. Como aduz a Resolução 225 do $\mathrm{CNJ} / 16$ :

"constitui-se como um conjunto ordenado e sistêmico de princípios, métodos, técnicas e atividades próprias, que visa à conscientização sobre fatores relacionais, institucionais e sociais motivadores de conflitos e violência, e por meio do qual os conflitos que geram dano, concreto ou abstrato[...]".

Com base ainda, na referida Resolução 225 do $C N J / 16$, para a solução de forma estruturada desses conflitos e da violência, mister a participação do ofensor, da vítima, bem como das suas famílias e dos demais envolvidos da comunidade direta ou indiretamente pelo fato delituoso.

Então, as práticas restaurativas serão coordenadas por facilitadores restaurativos preparados e capacitados em técnicas autocompositivas e consensuais 
de solução de conflitos inerentes da Justiça Restaurativa. Nesse aspecto, o facilitador precisa desenvolver a habilidade do foco, ou seja, da atenção plena, naquilo que pretende realizar. (GOLEMAN, 2014)

Em outras palavras, o foco é uma habilidade sutil, que atualmente tem sido cada vez mais difícil mantê-lo e cultivá-lo, "face as turbulências, aos conflitos e a exposição demasiada do ser humano com a tecnologia, a concentração cognitiva acaba se comprometendo, fragmentando, dando lugar a inteligência computacional; o que prejudica sistematicamente a capacidade empática" (GOLEMAN ,2014, p.11).

Alguns aspectos precisam ser trabalhados ou observados pelo facilitador restaurativo que lidará com os círculos conflitivos dentro do sistema de Justiça. Primeiramente, busca a atenção em foco, pois o cérebro absorve melhor a informação e ativa a capacidade de novas conexões neurais; para então, também se pensar profundamente.

Para restaurar a atenção, o silêncio e a meditação são os primeiros passos, para a retomada da reflexão e do foco. Com isso, vai ao encontro da autoconsciência que é a bússola interna de cada pessoa. Em seguida, observar como os outros nos veem. Isso tem importância no processo, para se trabalhar com o autoconhecimento ou a autorevelação.

Durante o atendimento nos círculos de conflitos o facilitador precisa manter o autocontrole, no sentido de regular suas emoções, bem como observar com os demais participantes estão se sentindo no encontro restaurativo. Por isso, da sensibilidade social e da compreensão do contexto sociocultural daqueles que ali se encontram, na expectativa de encontrarem uma solução adequada aos seus problemas.

Os processos circulares são as práticas que possibilitam o encontro das pessoas em um local para dialogarem acerca de algo que lhes causou dano. A forma de círculo significa a conexão com o universo e principalmente com os outros que estão à volta. Para que ocorra a junção de ideias e os sentimentos entre os envolvidos, precisa-se desejar fazer-se presente. Aceitar a proposta é participar pela rede de conversações. É fundamental que os agentes apropriem-se do ato, para que se estabeleça no círculo um alicerce de valores e um espaço seguro de responsabilização. As vítimas são as que mais necessitam dos elementos fundamentadores da Justiça Restaurativa e, nesse sentido, o dano é contra a segurança da comunidade. (PRANIS, 2010). 
A clareza disso representa a estrutura restaurativa, ou seja, o nível e o reconhecimento comunitário de também assumir a sua parcela de responsabilidade. Os facilitadores pela realização de um círculo precisam estabelecer uma comunicação respeitosa questionamentos como: o que a vítima está sentindo, pensando sobre o acontecido; ou o que poderia ser feito para auxiliar na cicatrização das feridas deixadas pelo trauma vivenciado.

Nesse mesmo sentido, outras peculiaridades imprescindíveis e que precisam ser observadas são: voz alta para chamar atenção, sem sarcasmo, depois moderação na entonação; olhar neutro e respirar antes de falar. Muitos danos poderiam ser evitados com a respiração adequada. As pessoas precisam estar felizes, por estar ali e se tratarem sensivelmente. A comunicação estabelecida é informal e a abordagem cuidadosa. (PRANIS, 2010). Trata-se, pois de um ato de amor, solidariedade e fraternidade.

Ser um facilitador na Justiça Restaurativa não se esgota na formação teórico-prático oferecida pelos Tribunais de Justiça do RS, vai além, como bem se pode compreender anteriormente. Ao facilitar o encontro entre a vítima, o ofensor, os familiares e a comunidade, se busca o consenso e a compreensão de que todos direta ou indiretamente foram e são responsáveis pelo dano e a suas implicações. Porém, a corresponsabilidade de se construir algo é a partir do presente. Não se espera com a metodologia do círculo de construção de paz, ou seja: com a prática restaurativa o perdão entre os participantes. Se espera qualificar o atendimento jurisdicional com o ofensor e a vítima. Sendo assim, ambos podem nesse espaço pelo princípio da voluntariedade e da participação, falar e ser escutado.

Por outro lado, se existir o gesto do perdão entre os envolvidos, enquanto valor isso não compromete o processo circular.Portanto, falar sobre o perdão dentro da Justiça Restaurativa não é simples, levando a algumas reflexões abordadas logo abaixo.

\section{O lugar do perdão na Justiça Restaurativa}

O perdão nos pensamentos modernos e contemporâneos pode ser considerado como uma virtude, ato de bondade ou de generosidade, compaixão e alteridade. Seu sentido é complexo e gera controvérsias quando também presente na Justiça Restaurativa. Para tanto, provoca reflexão crítica sobre sua 
viabilidade nas práticas e se efetivamente é uma busca dos envolvimentos, bem como se seria a principal finalidade do processo restaurativo.

Por ser a Justiça Restaurativa multidimensional, algumas autoras como a Kay Pranis trabalham com a espiritualidade e a força interior de cada participante no processo circular.

Além disso, existem muitas iniciativas de práticas restaurativas de organizações religiosas e cristãs, por exemplo no Brasil tem-se a Associação de Proteção e Assistência aos Condenados (APAC). "É uma entidade não governamental fundada em 1974 no município de São José dos Campos (SP), que atua sob a fiscalização do Ministério da Justiça e de Secretarias de Estado". Entre os seus objetivos estao implantar um novo processo de acompanhamento e reabilitação de presos nas respectivas unidades administrada nos 15 Estados, sob a premissa da participação comunitária, contando com pessoas voluntárias (ESPAÇOS, 2009) ${ }^{3}$.

Ao mesmo tempo, parece haver um interesse crescente referente ao potencial do perdão na prática de Justiça Restaurativa, na tentativa de favorecer um estado de espírito ou uma capacidade emocional capaz de beneficiar a reparação. O perdão é visto como uma capacidade emocional capaz de beneficiar a reparação, bem como uma possibilidade de reduzir a vontade da vingança e/ou aumentar a empatia, e assim favorecer aproximação das pessoas após a ruptura do tecido social, o que são fatores importantes nos procedimentos restaurativos.

Mas, ainda que tenha teoricamente uma proximidade, isso não significa que automaticamente um favorece o outro, pois muitos não estão dispostos a assumir a linguagem do restabelecimento da paz, como por exemplo o pedido de desculpas e a concessão do perdão por parte das vítimas ao ofensor. O que interessa significativamente no encontro ou na prática da Justiça Restaurativa é o sentimento de gratidão pela experiência vivenciada, que auxilia muito na recondução de suas vidas . Poder-se-ia pensar em um outro sentido de perdão nas práticas restaurativas, que é a compensação pelas perdas sofridas.

O hábito de pedir perdão, entendido como sendo ato de humilhação, ensina as pessoas a serem justas em vez de injustas, simplesmente para querer evitar esta humilhação. Entretanto, o perdão não pode ser descrito de dentro da

${ }^{3}$ ESPAÇOS Colaterais. Santa Luzia: Apacapac, 2009. Disponível em: http://www.colaterais.org/textos/apacapac. Acesso em: 24 ago. 2009 
estrutura formal de justiça, pois ao se perdoar, a ponto de ser misericordiosos com cada um, se não se punir nenhuma ofensa, falhar-se-á em tratar as pessoas conforme seus erros, como o conceito formal da justiça impõe a fazer. Se misericordiosos apenas para com alguns, mas não para com todos, então, a menos que observe uma norma concreta recomenda misericórdia em tal e tal caso, estar-se-á infringindo a justiça formal.

Como interagir com uma memória que insiste em lembrar meus atos do passado e não me deixa em paz? Parecem existir pelo menos duas possibilidades: o arrependimento e o remorso. A primeira é uma forma de transação quando eu assumo o mal feito e você me devolve o estado da inocência. O remorso, ao contrário, brota do sentido ou do reconhecimento do irreparável, da clarividência de que o sofrimento infringido está pregado em mim para a eternidade. Neste caso, a consciência acusa um dano irreparável e, portanto, inexpiável. “O remorso é este sinal de Caim, conforme o relato bíblico, quando Deus ordena uma terrível vingança a quem ouse matar ${ }^{4}$ Caim após ele expressar seu remorso por ter matado seu irmão". Uma explicação pode ser que o crime cometido não admita nem pagamento e nem expiação: Caim tem que viver. Não deve ser maltratado, pois esta dor poderá ser interpretada como uma possibilidade de expiação de sua culpa (MATE, 2008).

Ricoeur (2008, p. 196) afirma que o perdão é uma espécie de cura da memória, o acabamento de sua luta; liberta do peso da dívida, a memória fica liberada para grandes projetos. O perdão dá futuro à memória, pois uma memória curada é aquela que não desapareceu ou caiu no esquecimento, mas que, embora incômoda, perdeu seu caráter tóxico. O presente não está mais envenenado, excluindo a possibilidade do futuro. As feridas que restaram são capazes de influenciar a experiência sábia e podem ajudar outras pessoas (JESUDASAN; RÜPPEL, 2008).

Não é verdadeiramente certo que exista um pensamento moderno, no singular, e ainda menos certo que os séculos modernos possam ser inteligíveis fora de qualquer relação com o cristianismo. Das realidades que fazem alusão à do perdão, ou da própria realidade do perdão, de qualquer maneira foi fala-

\footnotetext{
${ }^{4}$ Gênesis 4,14-14: "Eis que hoje me lanças da face da terra; também da tua presença ficarei escondido; serei fugitivo e vagabundo na terra; e qualquer que me encontrar matar-me-á. O Senhor, porém, Ihe disse: Portanto quem matar a Caim, sete vezes sobre ele cairá a vingança. E pôs o Senhor um sinal emCaim, para que não o ferisse quem quer que o encontrasse."
} 
do sem propósito diretamente teológico: e isto permite assegurar uma unidade mínima (CANTO SPERBER, 2013. p. 787).

É ainda nos limites da desculpa, e na análise da magnanimidade que o perdão intervém para Descartes, em termos bem gregos. Os homens generosos, "ainda que vejam frequentemente que os outros cometem faltas que revelam sua fraqueza [...] são todavia inclinados a lhes desculpar do que a lhes condenar, e a acreditar que é mais por falta de conhecimento que por falta de boa vontade que eles a cometem". (CANTO SPERBER, 2013 p.787).

Sabe da existência controversa que é a do remorso, da lógica das paixões, que governa a vingança e a crueldade, uma lógica de clemência. O Deus de Spinoza não ama e nem odeia ninguém, é sinônimo da do amor pela generosidade. Quando Cristo aconselha resistência a violência pelos oprimidos, está em defesa da Boa República e da Justiça. (CANTO SPERBER, 2013 p.787).

Uma história conceitual do perdão e do perdoável deveria em seguida interrogar um outro grande teórico da escusa, Rousseau. "O homem é naturalmente bom, e a sociedade deprava e perverte os homens: o axiomático não tem subterfúgios". Na aurora da experiência, da maneira que ela é retomada na liminar das confissões, a consciência natural está "isenta dos remorsos do ímpio e dos crimes do malfeitor". (CANTO SPERBER, 2013 p.787).

O perdão, cuja concessão faria supor a responsabilidade do malfeitor é então desqualificado desde o início; ninguém responde mal, a não ser a relações sociais desprovidas de rosto, então ninguém pode ser absolvido. A misericórdia, por um lado, não conseguiria se alojar na ética Kantiana "o homem misericordioso não é um ser racional, mas um animal dotado também de razão". (CANTO SPERBER, 2013 p.787).

E por outro lado a afirmação da radicalidade do mal faz evidentemente entrar em cena algo que poderia ser perdoado e que, em última instância, solicita perdão divino. Seguramente o direito não conhece o perdão: o indivíduo que apela para o direito simplesmente abdica de qualquer desejo de vingança, para que a justiça seja racionalmente feita.

Ao observar a construção discursiva sobre o perdão por alguns pensadores modernos, percebe-se a complexidade que o seu sentido representa e implica dentro das relações conflituosas em sociedade. Esse ato em meio a justiça não pode ser confundido como direito, mas como uma atitude de homem nobre, vituoso e moral. 
O perdão aqui não é elementar para Justiça Restaurativa, mas em algumas circunstâncias é significativo para o ser humano em termos de conforto e espiritualidade.

Quando trata-se da alteridade compreende-se que o homem social interage e se conecta com o outro. Para Laplatine (2003),

\footnotetext{
A experiência da alteridade (e a elaboração dessa experiência) leva-nos a ver aquilo que nem teríamos conseguido imaginar, dada a nossa dificuldade em fixar nossa atenção no que nos é habitual, familiar, cotidiano, e que consideramos 'evidente'. Aos poucos, notamos que o menor dos nossos comportamentos (gestos, mímicas, posturas, reações afetivas) não tem realmente nada de 'natural'. Começamos, então, a nos surpreender com aquilo que diz respeito a nós mesmos, a nos espiar. O conhecimento (antropológico) da nossa cultura passa inevitavelmente pelo conhecimento das outras culturas; e devemos especialmente reconhecer que somos uma cultura possível entre tantas outras, mas não a única. (LAPLATINE, 2003. p. 12-13)
}

Para Levinas a alteridade é a relação do Eu com o outro, uma espécie de vínculo mútuo de respeito e reconhecimento na interação de convivência. Este ideal reflete instantaneamente com os princípios restaurativos, onde a dimensão maior está em restabelecer o laços e permitir que o outro mantenha o bom senso, a integridade, o bem estar, um com o outro.

\section{Considerações finais}

Neste presente trabalho buscou-se responder a seguinte indagação: A Justiça Restaurativa é a busca pelo perdão do outro? Com isso seria um exercício a alteridade? Para que se obtivesse êxito na resposta foi precisso compreender que dentro de uma comunidade ocorrem conflitos, vindos por desigualdades, pensamentos diferentes, interesses difusos, dificuldade de comunicação e falta de diálogo, o que consequentemente vem a ocorrência dos delitos.

As práticas restaurativas vem como uma possibilidade de encontro, reparação e não necessariamente o perdão, mas a compensação e o agradecimento. Existem diversas metodologias utilizadas pela Justiça Restaurativa, uma das mais conhecidas e aceitas por se aproximar dos valores e da espiritualidade humana são os círculos de construção da paz, com a finalidade precípua de restabelecer a comunicação e as relações sociais entre as pessoas. 
Assim, o diálogo é extremamente necessário, para buscar o perdão entre as pessoas, se assim desejarem, pois o importante é a compreensão e a clareza sobre o que aconteceu com elas, diante do crime. Todos devem estar cientes que toda ação acaba por gerar uma reação e esta pode ser positiva se compreendida de forma mais humana.

É importante ter o cuidado mútuo, a seriedade com a prática e a clareza de não reduzi-la ao simplismo. Dada a complexidade dos problemas e das instituições, bem como da instituicionalização da Justiça Restaurativa, se não repensada e encarada dentro do trabalho em rede, poderá se tornar mais uma ferramenta do direito penla para punir o ofensor e revitimizar a víitma.

Está-se diante de uma grande oportunidade de inovação jurítica de prática de justiça no Brasil, porém, as desigualdades sociais e a estratificação perpetuada culturalmente, inclusive no meio jurídico pode banalizar a ideia de restauração de justiça, se o homem não se permitir em "trocar as lentes", permitindo-se humanizar, e enxerguar o outro também como um ser humano, capaz , livre e legítimo como autor da sua própria história!

\section{REFERÊNCIAS}

BONNEN, Petronella Maria. A justiça restaurativa, um desafio para a educação. Orientação: Flávia Schilling. São Paulo: s.n. 2011. 260p.

CACHAPUZ, Rozane da Rosa. Mediação nos Conflitos \& Direito de Família. 1 ed., Jurua, 2003.

CANTO- SPERBER, Monique. Dicionário de ética e filosofia moral. Tradução Ana Maria Ribeiro - Althoff [et. Al]. - São Leopoldo, RS: Ed. UNISINOS, 2013, p.787.

COSTA, Márcio Luis. Levinas: uma introdução. Tradução de J. Thomaz Filho. Petrópolis: Vozes, 2000.

ESPAÇOS Colaterais. Santa Luzia: Apacapac, 2009. Disponível em: <http://www. colaterais.org/textos/apacapac>. Acesso em: 24 ago. 2009. 
GOLEMAN, Daniel. Foco: a atenção e seu papel fundamental para o sucesso. Rio de Janeiro: Objetiva, 2014.

GOMES, Luiz Flávio. Criminologia: introdução a seus fundamentos teóricos: introdução às bases criminológicas da Lei 9.099/95 - Lei dos juizados especiais criminais. GOMES, Luiz Flávio; Antonio GARCIA; Pablos de MOLINA: tradução GOMES, Luiz Flávio; GARCIA, Yebbin Morote; TANGERINO, David. 7 ed. São Paulo: Editora Revista dos Tribunais, 2010.

HELLER, Agnes. Além da Justiça. Rio de Janeiro: Civilização Brasileira, 1998.

JESUDASAN, Usha; RÜPPEL, Gerd. Pain, Remembrance, Healing. Geneve: World Council of Churches, 2008.

LAPLATINE, François. Aprender Antropologia. São Paulo: Brasiliense. pp. 12-13. 2003.

LIEBMANN, Marian. Restorative justice: how it works. London: Jessica Kinglsy Publishers, 2007.

MORAES, Tiago França. Mediação, conciliação e arbitragem. Revista Jus Navigandi, ISSN 1518-4862, Teresina, ano 17, n. 3346, 29 ago. 2012. Disponível em: <https:/ / jus.com.br/artigos/22520>. Acesso em: 29 maio 2017.

MATE, Reyes. Justicia de las victimas: Terrorismo, memoria, reconciliación. Barcelona: Anthropos, 2008. Página 142.

PRANIS, Kay. Processos Circulares. Tradução de Tônia Van Acker. São Paulo: Palas Athena, 2010

RICOEUR, Paul. O Justo. Martins Fontes: São Paulo. 2008.

SALES, Lília Maia de Morais. Justiça e mediação de conflitos. Belo Horizonte: Del Rey, 2004.

SANTANA, Luis F. Gordillo. La Justicia Restaurativa y La Mediación Penal. Iuestel. Portal Derechos, S. A., 1 ed., Espanha. Paracuellos de Jarama (Madrid), 2007. 
SUSIN, Luiz Carlos. O Homem Messiânico: uma introdução ao pensamento de Emmanuel Lévinas. Porto alegre/ Petrópolis: Escola Superior de Teologia São Lourenço de Brindes/Vozes, 1984.

VAN NESS, D. W.; STRONG, K. H. Restoring Justice: an introduction to Restorative Justice. New Providence, NJ: Matthew Bender \& Company, Inc., 2010, p. 21-22.

ZEHR, HOWARD. Trocando as lentes. Um novo foco sobre o crime e a justiça. Tradução de Tônia Van Acker. São Paulo: Palas Athena, 2008, p.257 